\title{
Natural history of ovarian high-grade serous carcinoma from time effects of ovulation inhibition and progesterone clearance of p53-defective lesions
}

\author{
$\mathrm{Na}-$ Yi Yuan $\mathrm{Wu}^{1} \cdot$ Chao Fang ${ }^{2} \cdot \mathrm{Hsuan}^{-S h u n} \mathrm{Huang}^{3} \cdot$ Jing Wang $^{1} \cdot$ Tang-Yuan $\mathrm{Chu}^{3,4}$
}

Received: 17 July 2019 / Revised: 26 August 2019 / Accepted: 28 August 2019 / Published online: 26 September 2019

(c) The Author(s), under exclusive licence to United States \& Canadian Academy of Pathology 2019

\begin{abstract}
High-grade serous carcinoma is the most common and devastating type of ovarian cancer; its etiology, mechanism of malignant transformation, and origin remain controversial. Recent studies have identified secretory cells at the fimbria of the fallopian tube as the cell-of-origin of high-grade serous carcinoma, acquiring TP53 mutation, evolving to tubal precursor lesions, including "p53 signature" and serous tubal intraepithelial carcinoma, and metastasizing to the ovary as clinically evident ovarian cancer. The etiological mechanisms associated with known epidemiological risk factors, i.e., ovulation and retrograde menstruation, have also been suggested. Mutagens and transforming growth factors, such as reactive oxygen species and insulin-like growth factor axis proteins, as well as the apoptosis-rescuing protein hemoglobin are abundantly present in the ovulatory follicular fluid and peritoneum fluid, which bathes the fimbrial epithelium, and induces malignant transformation after repeated exposure. In accordance with the proposed cleansing effect of progesterone from studies on oral contraceptive use or term pregnancy, a recent study indicated that the p53-null tubal epithelial cells are selectively cleared by progesterone depending on its progesterone receptor. In this report, by analyzing different time effects of oral contraceptive use or pregnancy in the prevention of ovarian cancer and by aligning them with the carcinogenic and cleansing clearance concepts of ovulation and progesterone, as well as the fact of progressive loss of progesterone receptor during tubal transformation, we deduced the natural history of ovarian high-grade serous carcinoma. The natural history begins at the first ovulation and spans for more than 30 years, taking 10 years from the normal tubal epithelium to the "p53 signature" status, another 15 years to progesterone receptor negative serous tubal intraepithelial carcinoma, and a final $5+$ years to highgrade serous carcinoma. The estimated natural history may help understand the pathogenesis of high-grade serous carcinoma and defines the window for early detection and chemoprevention.
\end{abstract}

Jing Wang

wangjing0081@hnca.org.cn

$\triangle$ Tang-Yuan Chu

hidrchu@gmail.com

1 Hunan Cancer Hospital, The Affiliated Cancer Hospital of Xiangya School of Medicine, Central South University, Changsha, China

2 Department of Anesthesiology, Third Xiangya Hospital, Central South University, Changsha, China

3 Department of Obstetrics and Gynecology, Buddhist Tzu Chi General Hospital, Hulien, Taiwan, ROC

4 Center for Prevention and Therapy of Gynecological Cancers, Department of Research, Buddhist Tzu Chi General Hospital, Hualien, Taiwan, ROC

\section{Introduction}

Neogrowth from the ovary is typically silent and diagnosed late. Late-occurring symptoms such as abdominal bloating, nausea, and urinary urgency are vague and often mistaken for gastrointestinal problems [1], which leads to high mortality. In nearly $80 \%$ of the cases, high-grade serous carcinoma, which is the most common type of epithelial ovarian carcinoma, is diagnosed after intraperitoneal spreading. Thus, epithelial ovarian carcinoma ranks as the seventh most common cause of cancer-related deaths in females worldwide [2]; this poor prognosis has not improved over the past several decades [3, 4]. This is fundamentally attributed to the unclear etiology and mechanisms of malignant transformation. The origin of ovarian high-grade serous carcinoma has been a matter of debate; it is thought to originate mostly from the fallopian tube fimbria, with 
secretory cells in the epithelium as the target of malignant transformation [5-7]. In addition, an increasing amount of evidence has pointed to incessant ovulation as the main etiological factor of ovarian high-grade serous carcinoma; therefore, the mechanism of ovulation-induced transformation is becoming clearer.

Herein, we review epidemiological evidence and current knowledge of ovulation-induced carcinogenesis, provide evidence for the cleansing effect of progesterone, and deduce the natural history of ovarian high-grade serous carcinoma originating from the fallopian tube fimbria.

\section{Epidemiological evidence of epithelial ovarian carcinoma as a disease caused by ovulation}

\section{Oral contraceptives use reduced risk of epithelial ovarian carcinoma}

The incessant ovulation theory proposed by Fathalla [8] in 1971 is the most widely accepted theory of ovarian carcinogenesis. A multitude of ovulation cycles has been proposed as a trigger of epithelial ovarian carcinoma [9-13]. Many largescale epidemiological studies and meta-analyses have concluded that the use of oral contraceptives, pregnancy, or lactation reduces the risk of epithelial ovarian carcinoma $[14,15]$. There is convincing evidence of risk reduction by oral contraceptive use [16-18]. A collaborative analysis of 45 epidemiological studies comprising a total of 23,257 women with epithelial ovarian carcinoma and 87,303 controls revealed that oral contraceptive use is associated with reduced risk of epithelial ovarian carcinoma. The longer the women used oral contraceptives, the greater the reduction, and the protection persisted for more than 30 years after oral contraceptive use ceased [19]. A well-designed population-based case-control study revealed that each year of oral contraceptive use provided a $5 \%$ reduction in the risk of epithelial ovarian carcinoma [20]. It is estimated that oral contraceptive use has averted $\sim 1700$ deaths from ovarian cancer in 1982 among US women aged 20-54 years [21], and more than half of all ovarian cancers in the United States could be prevented by oral contraceptive use for at least 4 years [21, 22].

\section{Parity reduces the risk of epithelial ovarian carcinoma}

The protective effect of pregnancy on epithelial ovarian carcinoma has been documented in Asian, European, and North American populations. Various studies have shown that parity significantly reduced the risk of epithelial ovarian carcinoma in women [23-25]. A collaborative analysis of 12 casecontrol studies, which collected 2197 patients with ovarian cancer and 8893 controls, demonstrated a $40 \%$ lower risk after the first birth [26], with each additional birth bringing another 15-20\% risk reduction [27]. The risk of ovarian cancer was reduced by $57 \%, 70 \%$, and $82 \%$ in women with parity of $1-2,3-5$, and $>5$ children, respectively [28]. Interestingly, although full-term pregnancy confers a strong and prolonged protection from epithelial ovarian carcinoma, the number of incomplete pregnancies or abortions failed to show a significant effect on epithelial ovarian carcinoma prevention in various studies [26, 29-31].

\section{Breastfeeding reduces the risk of epithelial ovarian carcinoma}

Most studies have indicated that breastfeeding lowers the risk of epithelial ovarian carcinoma. Compared with women who never breastfed their children, parous women who have breastfed showed a $10-40 \%$ reduction in the risk of epithelial ovarian carcinoma [23, 26, 32]. There is a trend toward increased protection with increasing lactation periods [28]. Some studies also showed that lactation in the initial months after delivery conferred stronger protection than lactation at later months [26, 29]. This protective effect of lactation on the risk of epithelial ovarian carcinoma is consistent with the hypotheses of incessant ovulation and retrograde menstruation being related to the genesis of ovarian cancer.

\section{Carcinogens in ovulatory follicular fluid and mechanism of transformation}

\section{Reactive oxygen species as the mutagen and hemoglobin as the apoptosis rescuer}

Transformation activity in human ovulatory follicular fluid was first demonstrated by the induction of tumorigenesis after direct injection into Trp53-null transgenic mice. After weekly injections of diluted (3\%) follicular fluid into the mammary fat pad, $\sim 60 \%$ of mice developed local lymphoma within 7 weeks [33]. As almost all ovarian highgrade serous carcinomas have the universal TP53 mutation as the first hit and early $\mathrm{Rb}$ pathway dysfunction in $67 \%$ of the cases [34], the transforming activity of follicular fluid was tested in different immortalized human fimbrial epithelial cell lines wherein the p53 and Rb systems were downregulated. Indeed, adding diluted follicular fluid to these cells induced the transformation phenotypes of anchorage-independent growth and xenograft tumorigenesis [35]. Interestingly, only more than half of the follicular fluid samples were actively transforming. These follicular fluid samples typically contain high levels of reactive oxygen species, which are indispensable for ovulation [36] and responsible for DNA double-strand breaks upon exposure to 
the fimbria [33]. We also found that these reactive oxygen species-exposed cells, although failing to induce p53mediated cell death, still undergo apoptosis via the membrane-bound NADPH oxidase. By sensing a high level of reactive oxygen species, NADPH oxidase initiates a cell death pathway and terminates cell transformation. However, in the presence of hemoglobin in the follicular fluid or pelvic fluid, reactive oxygen species are largely captured by hemoglobin extracellularly and sensed by NADPH oxidase as a survival cue. Cells exposed to this lowered level of reactive oxygen species after hemoglobin consumption still accumulate DNA double strand breaks and proceed to transformation [37]. This pelvic hemoglobin is most likely originated by retrograde menstruation. Multiple epidemiological studies have highlighted that tubal ligation and hysterectomy reduce the risk of ovarian cancer $[38,39]$.

\section{Insulin-like growth factor axis as the stemness activator and transformation promoter}

In addition to the mutagenic activity conferred by reactive oxygen species, follicular fluid also has a stemness activation and clonal expansion activity [35]. This is mainly conferred by the insulin-like growth factor axis, the proteins of which, including insulin-like growth factor binding protein 2 and insulin-like growth factor binding protein 6-bound insulin-like growth factor 2 (but not insulin-like growth factor 1), as well as the insulin-like growth factor binding proteo-lytic enzyme pregnancy-associated plasmatic protein $\mathrm{A}$, are all present in ovulatory follicular fluid. Using a depletion test for each of these components by monoclonal antibodies, each component of these insulinlike growth factor axis proteins was found to be essential for transformation [35]. The mechanism of action of follicular fluid-insulin-like growth factor 2 in fimbrial epithelial cells was also described. Upon engaging with glycosaminoglycans on the membrane of fimbrial epithelial cells, pregnancy-associated plasmatic protein A cleaves insulinlike growth factor binding protein $\mathrm{s}$ and releases bioactive insulin-like growth factor 2 in close proximity to the membrane receptor insulin-like growth factor-1R. Two signaling pathways downstream to insulin-like growth factor $-1 \mathrm{R}$ are involved: the AKT/NANOG pathway is responsible for stemness activation, and the AKT/mTOR pathway is responsible for cell survival and expansion [35].

The insulin-like growth factor axis does not induce transformational mutations by itself. Instead, it promotes a selective expansion of initiated cells, providing a driving force for cancer evolution. Taking the human fimbrial epithelial cell line FE25 as an example, the immortalized E6/ E7/hTERT cells showed a subdiploid karyotype with 42-43 chromosomes at passage 31 . At p115, this subdiploid clone showed more chromosomal changes, more derived/marker chromosomes, and the chromosomal number changed to 39-40. Moreover, a polyploid clone with 74-77 chromosomes and more severe copy number variations and severe aneuploidy arose. In xenograft tumors induced by follicular fluid co-injection, a more consistent karyotype containing 67-76 chromosomes with more severe copy number variation and chromosomal aberrations was observed, suggesting a clonal evolution and progression from the parental polypoid clone [35]. Thus, ovulatory follicular fluid provides both the mutational initiation (reactive oxygen species) and evolutionary promoting forces to drive the transformation of fimbrial epithelial cells (Fig. 1).

Ovulation is a well-known process of acute inflammation with inevitable injury to the ovarian surface and fimbrial epithelium. The same follicular fluid- insulin-like growth factor 2 signaling also functions to promote the stemness of fimbrial epithelium [35]. Thus, the insulin-like growth factor axis in follicular fluid serves a physiological role of regenerating injured tissues after ovulation. Malignant transformation seems to be a byproduct of ovulation, a payable price given the evolutionary need for reproduction.

\section{Epidemiological and molecular evidence supports the cleansing effect of progesterone on p53-defective tubal precancerous lesions}

\section{The effect of epithelial ovarian carcinoma risk reduction by oral contraceptive cannot be explained only by ovulation inhibition}

While ovulation suppression is known to reduce the risk of epithelial ovarian carcinoma, multiple studies have found the extent and the declining rate of the risk of epithelial ovarian carcinoma by oral contraceptive use surpasses what can be expected by ovulation inhibition alone. In a meta-analysis of the time effect of oral contraceptive use on ovarian cancer incidence, a sharp decline in ovarian cancer incidence right after the beginning of oral contraceptive use was noted. The rate of decline in the first 3 years was greater than those in later years [19] (Fig. 2). Other studies also showed that the protection gained from pregnancy or short-term oral contraceptive use was far superior to what could be expected when considering ovulation inhibition alone. Moreover, the ovarian cancer protection effect showed a very short latency period (3-6 months), even immediately after oral contraceptive use [40]. If the cancer preventing effect of oral contraceptive use was limited to ovulation inhibition or at the cancer initiation stage, given that follicular fluid-reactive oxygen species initiate the mutation, the onset of protection would occur at least 30 years after the initiation of use, which is obviously not the case. The immediate and marked effect of short-term 


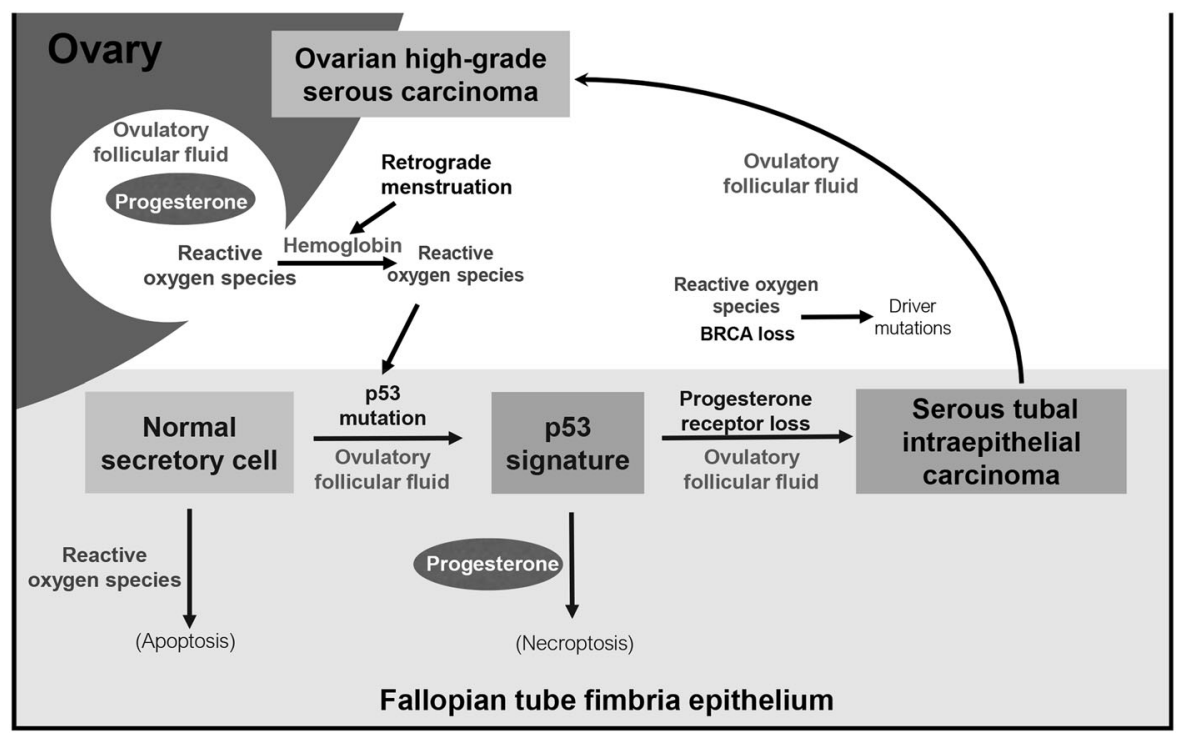

Fig. 1 Mechanism of fallopian tube fimbria transformation by ovulation and retrograde menstruation. A high level of reactive oxygen species released from follicular fluid would normally induce DNA mutation and consequent cell apoptosis. By curtailing excessive reactive oxygen species extracellularly, hemoglobin originating from retrograde menstruation makes the reactive oxygen species stress tolerable to the cells but still induces DNA mutation. When TP53 is mutated in stem or progenitor cells, growth factor from ovulatory follicular fluid, including insulin-like growth factor axis proteins, induce clonal expansion and proliferation to form p53-signature lesions. The same reactive oxygen species and ovulatory follicular

oral contraceptive use in lowering the epithelial ovarian carcinoma incidence would suggest a therapeutic effect of oral contraceptives on pre-existing cancer or ovarian precancerous cells.

\section{Evidence from progesterone-only contraceptives}

Progestin is the progesterone derivative widely used in oral contraceptives, typically in combination with estradiol derivatives. Unlike the estradiol dose, which has been decreasing in new oral contraceptive formulae, the dose of progesterone has not changed for decades. Despite the variable estradiol dose in different oral contraceptive formulae, the protection effect of these oral contraceptives on ovarian cancer has remained unchanged [19]. This would suggest that the protection activity of oral contraceptive is mainly derived from progesterone. Indeed, oral contraceptives with higher progesterone potency have a higher protective effect than those with lower progesterone potency [41]. The use of progestin-only oral contraceptives, such as depot medroxyprogesterone acetate [42-44] and levonorgestrel intrauterine system [45, 46], confers a strong protection from the risk of epithelial ovarian carcinoma. In a multicenter case-control study, women using medroxyprogesterone acetate for more than fluid may also be responsible for the progression of these lesions to serous tubal intraepithelial carcinoma and high-grade serous carcinoma. At ovulation, the luteinized ovarian follicle also contains a high level of progesterone, which induces necroptosis of TP53-mutated cells, providing transformation chemoprevention. The loss of progesterone receptor, failure of homologous recombination repair proteins (BRCA1/2), as well the periodical supply of mutagens and growth factors by incessant ovulation, drive the transformation and eventually metastasize to form high-grade serous carcinoma of the ovary and peritoneum

3 years had an $83 \%$ reduction (OR $0.17,95 \%$ CI $0.07-0.39, P<0.001)$ of the risk of epithelial ovarian carcinoma [42], a figure seemingly greater than that of combined oral contraceptive use [47].

\section{Pregnancy also confers a benefit beyond anovulation}

In studies about the effect of pregnancy and breastfeeding on the prevention of ovarian cancer, a similar dose-response effect was found. Each month of pregnancy and breastfeeding conferred a reduction in the risk of ovarian cancer of $2.6 \%$ and $2.4 \%$, respectively [32]. This effect was independent of parity and, as is the case for oral contraceptive use, cannot be explained by ovulation inhibition alone [24, 48]. Regarding pregnancy, maternal age is relevant when discussing the protective effect against ovarian cancer. Several studies indicate that age at pregnancy is more important than the number of completed pregnancies [49, 50]. In a case-control study adjusted for parity, older age at first and last births and a shorter time since the last birth were associated with significantly reduced risk of ovarian cancer [48]. Thus, completed pregnancies but not abortion (discussed later) were suggested to diminish the malignant transformed cells from the ovaries [51]. 


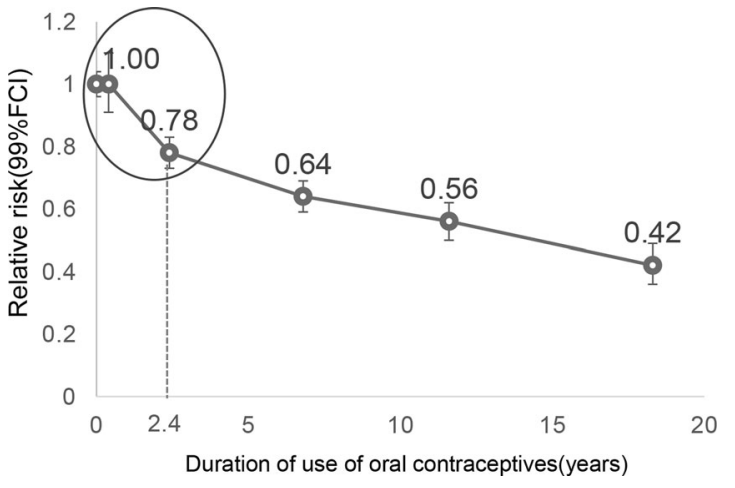

Fig. 2 Immediate short-term decrease of ovarian cancer risk during the first 5 years after oral contraceptive use. The slope of incidence decline is greater in the earlier years after oral contraceptive use. Adapted from Beral et al. 2008 [19]

\section{Progesterone may have a cleansing effect on early lesions of ovarian high-grade serous carcinoma}

The abovementioned early-onset and beyond-ovulationinhibition protective effect of oral contraceptives, as well as the protection provided by the last completed pregnancy regarding the risk of epithelial ovarian carcinoma can best be explained by a cleansing effect of progesterone. Progesterone is the hormone secreted by the corpus luteum of the ovary after ovulation to sustain the luteal phase of menstrual cycle. After embryo implantation, progesterone is produced by the growing placenta in increasing amounts. At term pregnancy, serum progesterone concentration reaches a level $(200 \mathrm{ng} / \mathrm{ml}), 20$-fold higher than the peak level $(10 \mathrm{ng} / \mathrm{ml})$ at the luteal phase. In contrast, progesterone level at the first trimester of pregnancy is only modestly increased. This may explain the lack of protection given by incomplete pregnancy (abortion) [23, 26, 28, 31].

\section{Progesterone may eliminate p53-defective lesions in the fallopian tube}

\section{The first and universal hit of TP53 in high-grade serous carcinoma}

Virtually all high-grade serous carcinomas, as well as its precursor tubal intraepithelial carcinoma, have TP53 mutation [52-56]. TP53 mutation is regarded as the first hit since the earliest tubal lesion showing a p53 signature is characterized by the clustering of histologically normal tubal secretory cells with accumulation of mutant p53 in the nucleus [52]. This signature, defined by aberrant $\mathrm{p} 53$ immunostaining in $12+$ consecutive secretory cell nuclei, represents a section of an area of p53 lesion that most likely arises from a p53 mutant progenitor after clonal expansion. The progesterone receptor-naive progenitor cell is resistant to progesterone until progesterone receptors are expressed after several rounds of cell division and differentiation, which explains why p53 signature always has a limited length in section (or diameter in the epithelial surface).

The cause of this TP53 mutation is unknown but is highly related to ovulation. Compared with women with p53-normal (type I) ovarian cancer, those with p53overexpressing (type II) ovarian cancer [57] had a greater number of lifetime ovulatory cycles. The study showed a positive correlation between the number of lifetime ovulation cycles and the likelihood of ovarian tumors harboring overexpressing mutant p53 [58]. As mentioned in the previous section, a high level of reactive oxygen species in follicular fluid exerts a mutagenic effect on the secretory cells of the fimbria $[33,37,59]$. Although it is difficult to prove ovulation causes de novo TP53 mutation, an initiation role of ovulation on the development of high-grade serous carcinoma is obvious, since epidemiological studies have showed a long-term protection from epithelial ovarian carcinoma induced by ovulation inhibition for up to three decades [20].

\section{Progesterone induces necroptosis of p53-defective fimbrial epithelial cells}

Since TP53 mutation is the earliest and universal feature of high-grade serous carcinoma, the cleansing effect of progesterone is likely to target p53-defective tubal epithelial cells. Using a Trp53-null transgenic mouse model and immortalized human fimbrial epithelial cells deficient in p53 (FE25), the cleansing effect of progesterone on p53-defective tubal epithelium was validated [60]. Diestrus (equivalent to the luteal phase in humans) progesterone supplementation at a dose $(5 \mathrm{mg} / \mathrm{kg}$ intraperitoneal in mice) equivalent to that present in follicular fluid after ovulation, one third of the serum level at full-term pregnancy, or six times of the luteal phase peak $[60,61]$, could eradicate the tubal epithelium, followed by a regeneration at proestrus. Supplementation during nondiestrus phases or at diestrus in wild-type Trp53 mice had no effect. Interestingly, these p53-defective tubal epithelial cells underwent necroptotic death instead of the apoptotic death typically observed during menstruation after progesterone withdrawal [62]. The cytolysis of progesterone-treated FE25 cells is mediated through the TNF- $\alpha /$ RIPK1/RIPK3/MLKL necroptotic pathway depending on the canonical signaling by progesterone receptor [60]. There was also a natural, but less radical, clearance of oviduct epithelium in Trp53-null mice at diestrus. These preclinical results suggest that p53-defective tubal precursor lesions in oviduct can be cleared by exogeneous or endogenous progesterone. This may also explain the marked difference in prevalence between p53-signature (50 and $75 \%$ ) and serous tubal intraepithelial carcinoma 
Table 1 Reasoning and deduction of the natural history of high-grade serous carcinoma developed from the fallopian tube fimbrial epithelium

\begin{tabular}{|c|c|c|c|}
\hline & Time effects in epidemiological and clinical studies & $\begin{array}{l}\text { Reasoning based on ovulatory carcinogens and } \\
\text { progesterone clearance of p53 lesions }\end{array}$ & $\begin{array}{l}\text { Implications on the natural history of } \\
\text { ovarian high-grade serous carcinoma }\end{array}$ \\
\hline 1 & $\begin{array}{l}\text { The protective effect of oral contraceptives was not } \\
\text { affected by age at first or last use. Women who used } \\
\text { oral contraceptives s for a year or more were } \\
\text { protected for at least } 30 \text { years after they stopped } \\
\text { using. Each year of oral contraceptives use provided } \\
\text { a } 5 \% \text { reduction }(95 \% \text { CI: } 2-8 \%) \text { in risk of ovarian } \\
\text { cancer, up to an OR of } 0.18(0.08-0.39) \text { [20,74]. }\end{array}$ & $\begin{array}{l}\text { Ovulation contributes to the whole process of } \\
\text { transformation by promoting mutagenesis and } \\
\text { clonal expansion, beginning at the first ovulation } \\
\text { and progresses along with ovulations during the } \\
\text { reproductive age. }\end{array}$ & $\begin{array}{l}\text { The transformation involves with } \\
\text { ovulation in the whole reproductive age. } \\
\text { The course takes at least } 30 \text { years. }\end{array}$ \\
\hline 2 & $\begin{array}{l}\text { Even }<1 \text { year of anovulation by oral contraceptives } \\
\text { or pregnancy was associated with a remarkably } \\
\text { decrease of risk. The effect is far beyond that } \\
\text { predicted by anovulation }[20,32,40,71] \text {. }\end{array}$ & $\begin{array}{l}\text { This is compatible with the clearance effect of } \\
\text { progesterone on progesterone receptor-expressing, } \\
\text { p53-null tubal lesions (i.e., p53 signature and serous } \\
\text { tubal intraepithelial lesion) [60]. }\end{array}$ & $\begin{array}{l}\text { The natural history of tubal transformation } \\
\text { is terminated by progesterone unless } \\
\text { progesterone receptor is lost. }\end{array}$ \\
\hline 3 & $\begin{array}{l}\text { The protection by short duration }(<1 \text { year) oral } \\
\text { contraceptives use occurred among recent users, } \\
\text { within } 20 \text { years before diagnosis [20]. }\end{array}$ & $\begin{array}{l}\text { The p53-null specific clearance effect of P4 is } \\
\text { effective since } 20 \text { years before the diagnosis when } \\
\text { the first p53 lesion (p53 signature) is acquired. }\end{array}$ & $\begin{array}{l}\text { Time from acquisition of p53 signature to } \\
\text { diagnosis of ovarian high-grade serous } \\
\text { carcinoma is around } 20 \text { years. }\end{array}$ \\
\hline 4 & $\begin{array}{l}\text { Modeling based on genetic alteration and lesion- } \\
\text { specific proliferation rates indicated serous tubal } \\
\text { intraepithelial carcinoma may progress to carcinoma } \\
\text { in } 6 \text { years [72]. }\end{array}$ & $\begin{array}{l}\text { The rapid progression may be due to the loss of } \\
\text { progesterone and progesterone receptor in p53 } \\
\text { lesions after menopause, resulting in a rocketing of } \\
\text { ovarian high-grade serous carcinoma incidence } \\
\text { after menopause }[69,70] \text {. }\end{array}$ & $\begin{array}{l}\text { The history serous tubal intraepithelial } \\
\text { carcinoma is about } 5 \text { years. That of } \\
\text { p53 signature is } 15(20-5) \text { years and that } \\
\text { between normal and p53 signature is } 10 \\
(30-10) \text { years. }\end{array}$ \\
\hline 5 & $\begin{array}{l}\text { Ovarian high-grade serous carcinoma is rarely } \\
\text { diagnosed at an early stage, even under intensive } \\
\text { yearly surveillance [75]. }\end{array}$ & $\begin{array}{l}\text { Ovarian high-grade serous carcinoma develops } \\
\text { rapidly from serous tubal intraepithelial carcinoma } \\
\text { to high-grade serous carcinoma. }\end{array}$ & $\begin{array}{l}\text { Serous tubal intraepithelial carcinoma } \\
\text { develops to clinically evident (stage } 3 \text { ) } \\
\text { high-grade serous carcinoma in } 1 \text { year. }\end{array}$ \\
\hline
\end{tabular}

A summary of the natural history of high-grade serous carcinoma based on epidemiological and clinical reports. The deduced natural history is showed in Fig. 3, where progesterone receptor loss can occur at different stages with a dramatic increase after menopause

$(0.2-0.7$ and $2 \%)$ lesions in the fallopian tube of normal women and BRCA1/2 carriers, respectively [52, 63-65].

The cleansing effect of progesterone on p53 lesions leads to chemoprevention measures of ovarian high-grade serous carcinoma, i.e., encouraging pregnancy, even at old age, and periodical progesterone supplementation to remove tubal precancerous lesions. The study also predicts downregulation of progesterone receptor is essential in the development of ovarian high-grade serous carcinoma. Indeed, there is a progressive loss of progesterone receptor expression in the development of high-grade serous carcinoma, from an exclusive expression in the normal tubal epithelium, to $73 \%$ in p53 signature, $20 \%$ in serous tubal intraepithelial carcinoma STIC and $7.5 \%$ in high-grade serous carcinomas [66-68]. Therefore, most progesterone receptor-intact p53 signature and a minority of serous tubal intraepithelial carcinoma will undergo progesterone clearance.

The cleansing effect of progesterone also helps to explain a puzzling feature of epithelial ovarian carcinoma: more than $85 \%$ of cases are diagnosed after menopause with a median age at high-grade serous carcinoma diagnosis of 57 years [69]. While the long latency from cancer initiation to clinical disease may explain the old age of onset, the rocketing of incidence after menopause can best be explained by the loss of cyclic progesterone clearance after menopause. Expression of progesterone receptor-A in fallopian tube epithelium decreases dramatically after menopause. In the five reported postmenopausal cases of p53 signature, expression of progesterone receptor-A was also extremely low, with a labeling index of $0 \%, 0 \%, 0 \%$,
$2 \%, 15 \%$, and $0 \%$, respectively. By contrast, expression level of estrogen receptor- $\alpha$ were $100 \%, 27 \%, 100 \%, 91 \%$, and $100 \%$, respectively [70].

\section{The natural history of high-grade serous carcinoma developing from the oviduct}

Based on the plethora of information on the preventive and p53-null specific cleansing effects of oral contraceptive and progesterone on the genesis of high-grade serous carcinoma, we managed to deduce the natural history of highgrade serous carcinoma. The time effects disclosed from the epidemiological and clinical studies are particularly illuminating. These include the length of protection after discontinuing use, effect of age at first or last use, the minimal duration of use required for protection, the time from the onset of use to the onset of protection, and how long before the diagnosis can the cleansing effect still be valid and when does it become refractory [20, 32, 40, 71]. Given these timeeffect data and taking into consideration the clearance of p53 lesions by progesterone and the status of progesterone receptor loss in lesions of different severity, as well as a mathematic modeling based on the genetic alterations and the proliferation rates in p53 lesions of different severity [72], we were able to estimate the time to progression at different steps. Table 1 and Fig. 3 summarize this reasoning and estimation with translation to the time courses. The deduced natural history spans for at least 30 years, starting from the first ovulation with acquisition of DNA doublestrand breaks. At year 10, the first hit at TP53 on stem/ progenitor cells starts the p53 signature, after which another 
Fig. 3 Natural history of highgrade serous carcinoma developing from fallopian tube epithelium

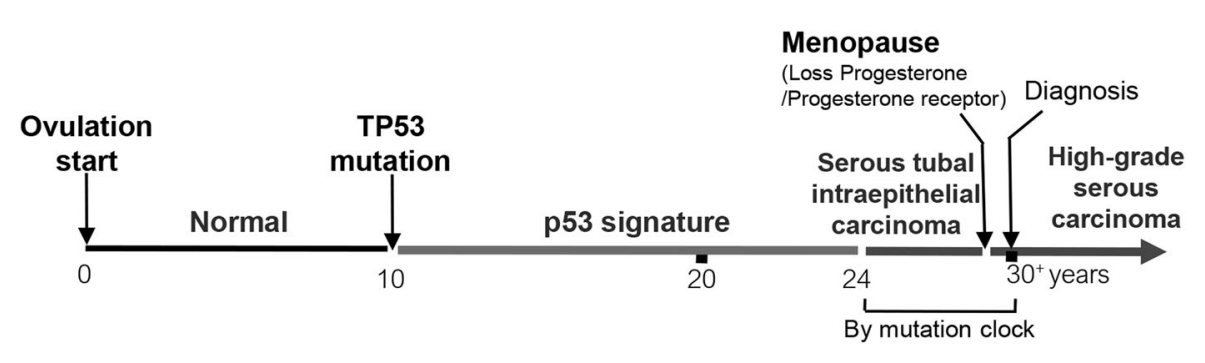

$+5 \%$ risk by each year of ovulation

Progesterone clearance of $\mathrm{p} 53$ lesion (Interrupted by menopause)

20 Years
20 years are necessary for the progression to a typical serous tubal intraepithelial carcinoma lesion and 6 years to early high-grade serous carcinoma (Fig. 3). These figures are consistent with an estimation based on the analysis of published data for serous carcinoma obtained from BRCAl carriers undergoing prophylactic bilateral salpingo-oophorectomy, where in a 4.3-year life expectancy was estimated for early stage (carcinoma in situ, stage I/II) occult highgrade serous carcinoma and about 1 year as stage $\mathrm{III}^{+}$ cancers before they become clinically apparent [73].

There are limitations to this deduction of natural history. Although there is a large amount of epidemiological evidence supporting the long-term protection of epithelial ovarian carcinoma by oral contraceptive and the rapidonset cleansing effect of progesterone, there is only one study [20] analyzing the comprehensive time effects of oral contraceptive use and epithelial ovarian carcinoma protection. A direct clinical trial about the efficacy of preoperative progesterone use in reducing the tubal $\mathrm{p} 53$ lesion in BRCA carriers is pertinently in need. A largescale systemic study of the progesterone receptor status in tubal intraepithelial lesions and the epidemiological correlates is also needed.

\section{Conclusion}

The carcinogenic process and mechanism of transformation are becoming clearer. Among the multiple carcinogens discovered, follicular fluid-reactive oxygen species drive the mutagenesis, hemoglobin from retrograde menstruation captures the excessive reactive oxygen species, switching reactive oxygen species-stressed cells from apoptosis to survival, and follicular fluid-insulin-like growth factor activates and expands the initiated cells for malignant transformation. Progesterone in follicular fluid, during pregnancy or taken exogenously, provides physiological protection and chemoprevention. progesterone receptor loss leads to p53 lesions escaping the progesterone protection and progressing to high-grade serous carcinoma. This study provides the first comprehensive estimation of the natural history of tubal carcinogenesis and high-grade serous carcinoma development. It helps in the understanding of pathogenesis and defines the window for early detection and chemoprevention by progesterone. However, some questions and challenges remain, such as defining and identifying of $\mathrm{p} 53$ lesions that are sensitive or refractory to progesterone, of the precancerous lesion that should be the target of early detection, and of biomarkers for diagnostic screening purposes and determining the optimal dose, interval, and timing of progesterone chemoprevention.

Acknowledgements This study was partly supported by grants of the Ministry of Science and Technology, Taiwan (MOST 107-2314-B303-013-MY3(1/3), and the clinical research center in gynecologic cancer, Hunan Cancer Hospital (2016SK4005), and the National Natural Science Foundation of China (2016YFC1303703, 81972836, 81603207, 2017JJ3189).

\section{Compliance with ethical standards}

Conflict of interest The authors declare that they have no conflict of interest.

Publisher's note Springer Nature remains neutral with regard to jurisdictional claims in published maps and institutional affiliations.

\section{References}

1. Smith LH, Morris CR, Yasmeen S, Parikh-Patel A, Cress RD, Romano PS. Ovarian cancer: can we make the clinical diagnosis earlier? Cancer. 2005;104:1398-407.

2. Siegel RL, Miller KD, Jemal A. Cancer statistics, 2018. CA Cancer J Clin. 2018;68:7-30.

3. Hennessy BT, Coleman RL, Markman M. Ovarian cancer. Lancet. 2009;374:1371-82.

4. Baldwin LA, Huang B, Miller RW, Tucker T, Goodrich ST, Podzielinski I, et al. Ten-year relative survival for epithelial ovarian cancer. Obstet Gynecol. 2012;120:612-8. 
5. Levanon K, Crum C, Drapkin R. New insights into the pathogenesis of serous ovarian cancer and its clinical impact. J Clin Oncol. 2008;26:5284-93.

6. Vang R, Shih IeM, Kurman RJ. Fallopian tube precursors of ovarian low- and high-grade serous neoplasms. Histopathology. 2013;62:44-58.

7. Leeper K, Garcia R, Swisher E, Goff B, Greer B, Paley P. Pathologic findings in prophylactic oophorectomy specimens in high-risk women. Gynecologic Oncol. 2002;87:52-6.

8. Fathalla MF. Incessant ovulation-a factor in ovarian neoplasia? Lancet. 1971;2:163.

9. Gates MA, Rosner BA, Hecht JL, Tworoger SS. Risk factors for epithelial ovarian cancer by histologic subtype. Am J Epidemiol. 2010;171:45-53.

10. Pelucchi C, Galeone C, Talamini R, Bosetti C, Montella M, Negri E, et al. Lifetime ovulatory cycles and ovarian cancer risk in 2 Italian case-control studies. Am J Obstet Gynecol. 2007;196:83.e1-7.

11. Casagrande JT, Louie EW, Pike MC, Roy S, Ross RK, Henderson BE. "Incessant ovulation" and ovarian cancer. Lancet. 1979;2:170-3.

12. Fleming JS, Beaugie CR, Haviv I, Chenevix-Trench G, Tan OL. Incessant ovulation, inflammation and epithelial ovarian carcinogenesis: revisiting old hypotheses. Mol Cell Endocrinol. 2006;247:4-21.

13. Purdie DM, Bain CJ, Siskind V, Webb PM, Green AC. Ovulation and risk of epithelial ovarian cancer. Int J Cancer. 2003;104:228-32.

14. Holschneider CH, Berek JS. Ovarian cancer: epidemiology, biology, and prognostic factors. Semin surgical Oncol. 2000;19:3-10.

15. Havrilesky LJ, Moorman PG, Lowery WJ, Gierisch JM, Coeytaux $\mathrm{RR}$, Urrutia RP, et al. Oral contraceptive pills as primary prevention for ovarian cancer: a systematic review and meta-analysis. Obstet Gynecol. 2013;122:139-47.

16. Bosetti C, Negri E, Trichopoulos D, Franceschi S, Beral V, Tzonou A, et al. Long-term effects of oral contraceptives on ovarian cancer risk. Int J Cancer. 2002;102:262-5.

17. Modugno F, Ness RB, Allen GO, Schildkraut JM, Davis FG, Goodman MT. Oral contraceptive use, reproductive history, and risk of epithelial ovarian cancer in women with and without endometriosis. Am J Obstet Gynecol. 2004;191:733-40.

18. Burkman R, Schlesselman JJ, Zieman M. Safety concerns and health benefits associated with oral contraception. Am J Obstet Gynecol. 2004;190:S5-22.

19. Beral V, Doll R, Hermon C, Peto R, Reeves G. Ovarian cancer and oral contraceptives: collaborative reanalysis of data from 45 epidemiological studies including 23,257 women with ovarian cancer and 87,303 controls. Lancet. 2008;371:303-14.

20. Lurie G, Wilkens LR, Thompson PJ, McDuffie KE, Carney ME, Terada KY, et al. Combined oral contraceptive use and epithelial ovarian cancer risk: time-related effects. Epidemiology. 2008; 19:237-43.

21. Cancer and Steroid Hormone Study of the Centers for Disease Control and the National Institute of Child Health and Human Development.The reduction in risk of ovarian cancer associated with oral-contraceptive use. N Eng J Med. 1987;316:650-5.

22. Weiss NS, Lyon JL, Liff JM, Vollmer WM, Daling JR. Incidence of ovarian cancer in relation to the use of oral contraceptives. Int $\mathbf{J}$ Cancer. 1981;28:669-71.

23. Risch HA, Marrett LD, Howe GR. Parity, contraception, infertility, and the risk of epithelial ovarian cancer. Am J Epidemiol. 1994;140:585-97.

24. Pike MC, Pearce CL, Peters R, Cozen W, Wan P, Wu AH. Hormonal factors and the risk of invasive ovarian cancer: a populationbased case-control study. Fertil Steril. 2004;82:186-95.

25. Yang CY, Kuo HW, Chiu HF. Age at first birth, parity, and risk of death from ovarian cancer in Taiwan: a country of low incidence of ovarian cancer. International journal of gynecological cancer: official journal of the International Gynecological Cancer. Society. 2007;17:32-6.
26. Whittemore AS, Harris R, Itnyre J. Characteristics relating to ovarian cancer risk: collaborative analysis of 12 US case-control studies. II. Invasive epithelial ovarian cancers in white women. Collaborative Ovarian Cancer Group. Ame J Epidemiol. 1992;136:1184-203.

27. Riman T, Nilsson S, Persson IR. Review of epidemiological evidence for reproductive and hormonal factors in relation to the risk of epithelial ovarian malignancies. Acta Obst Gynecol Scand. 2004;83:783-95.

28. Yen ML, Yen BL, Bai CH, Lin RS. Risk factors for ovarian cancer in Taiwan: a case-control study in a low-incidence population. Gynecologic Oncol. 2003;89:318-24.

29. Booth M, Beral V, Smith P. Risk factors for ovarian cancer: a case-control study. Br J Cancer. 1989;60:592-8.

30. Cramer DW, Hutchison GB, Welch WR, Scully RE, Ryan KJ. Determinants of ovarian cancer risk. I. Reproductive experiences and family history. J Natl Cancer Inst. 1983;71:711-6.

31. Purdie D, Green A, Bain C, Siskind V, Ward B, Hacker N, et al. Reproductive and other factors and risk of epithelial ovarian cancer: an Australian case-control study. Survey of Women's Health Study Group. International journal of cancer. J Int Cancer. 1995;62:678-84.

32. Gwinn ML, Lee NC, Rhodes PH, Layde PM, Rubin GL. Pregnancy, breast feeding, and oral contraceptives and the risk of epithelial ovarian cancer. J Clin Epidemiol. 1990;43: 559-68.

33. Huang HS, Chu SC, Hsu CF, Chen PC, Ding DC, Chang MY, et al. Mutagenic, surviving and tumorigenic effects of follicular fluid in the context of p53 loss: initiation of fimbria carcinogenesis. Carcinogenesis. 2015;36:1419-28.

34. Bell D, Berchuck A, Birrer M, Chien J, Cramer D, Dao F, et al. Integrated genomic analyses of ovarian carcinoma. Nature. 2011;474:609-15

35. Hsu CF, Huang HS, Chen PC, Ding DC, Chu TY. IGF-axis confers transformation and regeneration of fallopian tube fimbria epithelium upon ovulation. EBioMedicine. 2019;41:597-609.

36. Shkolnik K, Tadmor A, Ben-Dor S, Nevo N, Galiani D, Dekel N. Reactive oxygen species are indispensable in ovulation. PNAS. 2011;108:1462-7.

37. Huang HS, Hsu CF, Chu SC, Chen PC, Ding DC, Chang MY, et al. Haemoglobin in pelvic fluid rescues fallopian tube epithelial cells from ROS stress and apoptosis. J Pathol. 2016;240:484-94.

38. Cibula D, Widschwendter M, Majek O, Dusek L. Tubal ligation and the risk of ovarian cancer: review and meta-analysis. Hum Reprod Update. 2011;17:55-67.

39. Sieh W, Salvador S, McGuire V, Weber RP, Terry KL, Rossing MA, et al. Tubal ligation and risk of ovarian cancer subtypes: a pooled analysis of case-control studies. Int $\mathrm{J}$ Epidemiol. 2013;42:579-89.

40. Siskind V, Green A, Bain C, Purdie D. Beyond ovulation: oral contraceptives and epithelial ovarian cancer. Epidemiology. 2000;11:106-10.

41. Maxwell GL, Schildkraut JM, Calingaert B, Risinger JI, Dainty L, Marchbanks PA, et al. Progestin and estrogen potency of combination oral contraceptives and endometrial cancer risk. Gynecologic Oncol. 2006;103:535-40.

42. Wilailak S, Vipupinyo C, Suraseranivong V, Chotivanich K, Kietpeerakool C, Tanapat Y, et al. Depot medroxyprogesterone acetate and epithelial ovarian cancer: a multicentre case-control study. BJOG. 2012;119:672-7.

43. Knowlden HA. The pill and cancer: a review of the literature. A case of swings and roundabouts? J Adv Nurs. 1990;15:1016-20.

44. Urban M, Banks E, Egger S, Canfell K, O'Connell D, Beral V, et al. Injectable and oral contraceptive use and cancers of the breast, cervix, ovary, and endometrium in black South African women: case-control study. PLoS Med. 2012;9:e1001182. 
45. Soini T, Hurskainen R, Grenman S, Maenpaa J, Paavonen J, Pukkala E. Cancer risk in women using the levonorgestrel-releasing intrauterine system in Finland. Obstet Gynecol. 2014;124:292-9.

46. Soini T, Hurskainen R, Grenman S, Maenpaa J, Paavonen J, Pukkala E. Impact of levonorgestrel-releasing intrauterine system use on the cancer risk of the ovary and fallopian tube. Acta Oncol. 2016;55:1281-4.

47. Risch HA. Hormonal etiology of epithelial ovarian cancer, with a hypothesis concerning the role of androgens and progesterone. $\mathrm{J}$ Natl Cancer Inst. 1998;90:1774-86.

48. Whiteman DC, Siskind V, Purdie DM, Green AC. Timing of pregnancy and the risk of epithelial ovarian cancer. Cancer epidemiology, biomarkers \& prevention: a publication of the American Association for Cancer Research, cosponsored by the American Society of Preventive. Oncology. 2003;12:42-6.

49. Moorman PG, Calingaert B, Palmieri RT, Iversen ES, Bentley $\mathrm{RC}$, Halabi S, et al. Hormonal risk factors for ovarian cancer in premenopausal and postmenopausal women. Am J Epidemiol. 2008;167:1059-69.

50. Adami HO, Hsieh CC, Lambe M, Trichopoulos D, Leon D, Persson I, et al. Parity, age at first childbirth, and risk of ovarian cancer. Lancet. 1994;344:1250-4.

51. Cooper GS, Schildkraut JM, Whittemore AS, Marchbanks PA. Pregnancy recency and risk of ovarian cancer. Cancer Causes Control. 1999;10:397-402.

52. Folkins AK, Jarboe EA, Saleemuddin A, Lee Y, Callahan MJ, Drapkin R, et al. A candidate precursor to pelvic serous cancer (p53 signature) and its prevalence in ovaries and fallopian tubes from women with BRCA mutations. Gynecologic Oncol. 2008;109:168-73.

53. Lee Y, Miron A, Drapkin R, Nucci MR, Medeiros F, Saleemuddin A, et al. A candidate precursor to serous carcinoma that originates in the distal fallopian tube. J Pathol. 2007;211:26-35.

54. Kindelberger DW, Lee Y, Miron A, Hirsch MS, Feltmate C, Medeiros F, et al. Intraepithelial carcinoma of the fimbria and pelvic serous carcinoma: evidence for a causal relationship. Am J surgical Pathol. 2007;31:161-9.

55. Ahmed AA, Etemadmoghadam D, Temple J, Lynch AG, Riad M, Sharma R, et al. Driver mutations in TP53 are ubiquitous in high grade serous carcinoma of the ovary. J Pathol. 2010;221:49-56.

56. Kuhn E, Kurman RJ, Vang R, Sehdev AS, Han G, Soslow R, et al. TP53 mutations in serous tubal intraepithelial carcinoma and concurrent pelvic high-grade serous carcinoma-evidence supporting the clonal relationship of the two lesions. J Pathol. 2012;226:421-6.

57. Kurman RJ, Shih IeM. The dualistic model of ovarian carcinogenesis: revisited, revised, and expanded. Am J Pathol. 2016;186:733-47.

58. Schildkraut JM, Bastos E, Berchuck A. Relationship between lifetime ovulatory cycles and overexpression of mutant p53 in epithelial ovarian cancer. J Natl Cancer Inst. 1997;89:932-8.

59. Bahar-Shany K, Brand H, Sapoznik S, Jacob-Hirsch J, Yung Y, Korach J, et al. Exposure of fallopian tube epithelium to follicular fluid mimics carcinogenic changes in precursor lesions of serous papillary carcinoma. Gynecologic Oncol. 2014;132:322-7.

60. Wu NY, Huang HS, Chao TH, Chou HM, Fang C, Qin CZ, et al. Progesterone prevents high-grade serous ovarian cancer by inducing necroptosis of p53-defective fallopian tube epithelial cells. Cell Rep. 2017;18:2557-65.

61. Ottoson UB, Carlstrom K, Damber JE, von Schoultz B. Serum levels of progesterone and some of its metabolites including deoxycorticosterone after oral and parenteral administration. Br J Obstet Gynaecol. 1984;91:1111-9.

62. Armstrong GM, Maybin JA, Murray AA, Nicol M, Walker C, Saunders PTK, et al. Endometrial apoptosis and neutrophil infiltration during menstruation exhibits spatial and temporal dynamics that are recapitulated in a mouse model. Sci Rep. 2017;7:17416.

63. Rabban JT, Garg K, Crawford B, Chen LM, Zaloudek CJ. Early detection of high-grade tubal serous carcinoma in women at low risk for hereditary breast and ovarian cancer syndrome by systematic examination of fallopian tubes incidentally removed during benign surgery. Am J surgical Pathol. 2014;38:729-42.

64. Meserve EEK, Brouwer J, Crum CP. Serous tubal intraepithelial neoplasia: the concept and its application. Mod Pathol. 2017;30:710-21.

65. Saleemuddin A, Folkins AK, Garrett L, Garber J, Muto MG, Crum CP, et al. Risk factors for a serous cancer precursor ("p53 signature") in women with inherited BRCA mutations. Gynecologic Oncol. 2008;111:226-32.

66. Nafisi H, Ghorab Z, Ismill N, Dube V, Plotkin A, Han G, et al. Immunophenotypic analysis in early mullerian serous carcinogenesis. Int J Gynecol Pathol. 2015;34:424-36.

67. Lau KM, Mok SC, Ho SM. Expression of human estrogen receptor-alpha and -beta, progesterone receptor, and androgen receptor mRNA in normal and malignant ovarian epithelial cells. PNAS. 1999;96:5722-7.

68. Sieh W, Kobel M, Longacre TA, Bowtell DD, deFazio A, Goodman MT, et al. Hormone-receptor expression and ovarian cancer survival: an ovarian tumor tissue analysis consortium study. Lancet Oncol. 2013;14:853-62.

69. Jayson GC, Kohn EC, Kitchener HC, Ledermann JA. Ovarian cancer. Lancet. 2014;384:1376-88.

70. Urabe R, Hachisuga T, Ueda T, Kawagoe T, Kurita T, Kagami S, et al. Effect of menopause on hormonal receptors in ampullae of the fallopian tube with a special reference to the p53 signature. Int J Women's Health. 2017;9:163-9.

71. Greer JB, Modugno F, Allen GO, Ness RB. Short-term oral contraceptive use and the risk of epithelial ovarian cancer. Am J Epidemiol. 2005;162:66-72.

72. Wu RC, Wang $\mathrm{P}$, Lin SF, Zhang M, Song Q, Chu T, et al. Genomic landscape and evolutionary trajectories of ovarian cancer precursor lesions. J Pathol. 2019;248:41-50.

73. Brown PO, Palmer C. The preclinical natural history of serous ovarian cancer: defining the target for early detection. PLoS Med. 2009;6:e1000114.

74. Riman T, Dickman PW, Nilsson S, Correia N, Nordlinder H, Magnusson CM, et al. Risk factors for invasive epithelial ovarian cancer: results from a Swedish case-control study. Am J Epidemiol. 2002;156:363-73.

75. Buys SS, Partridge E, Black A, Johnson CC, Lamerato L, Isaacs C, et al. Effect of screening on ovarian cancer mortality: 'the prostate, lung, colorectal and ovarian (PLCO) cancer screening randomized controlled trial. JAMA. 2011;305:2295-303. 